\title{
Carbon incorporation in ZnSe grown by metalorganic chemical vapor deposition
}

\author{
Konstantinos P. Giapis and Klays F. Jensen \\ Department of Chemical Fngineering and Matenials Science, University of Minnesota, Minneapolis, \\ Minnesota 55455 \\ J. E. Potts and Steven J. Pachuta \\ 3 M Company, 201-1N-35 3M Center, St. Paul, Minnesota 55144
}

(Received 24 March 1989; accepted for publication 26 May 1989)

Carbon incorporation in ZnSe flims grown by metalorganic chemical vapor deposition is reported. Secondary-ion mass spectrometry measurements in ZaSe fims grown from methylallylselenide and dimethylzine show an enhanced carbon accumulation at the interface between $\mathrm{ZnSe}$ and GaAs. The carbon incorporation in the bulk ZnSe increases with the VI/I ratio and for a value of VI/II $=3-4$, the amount of incorporated carbon abruptly jumps to concentrations of $10^{21} \mathrm{~cm}^{-3}$, whereupon the films become polycrystalline. A new shallow peak $I^{C}$ at $2.7920 \mathrm{eV}$ dominates the near-band-edge low-temperature photoluminescence spectra of all carbon-contaminated $\mathrm{ZnSe}$ fims. The intensity and linewidth of $I^{c}$ increase with the $V I / I I$ ratio in a similar manner to the carbon concentration. This peak is proposed to be due to the radiative decay of excitons bound to a complex defect, which is associated with the presence of carbon in the films.

Carbon is a possible impurity in the metalorganic chemical vapor deposition (MOCVD) of compound semiconductors since it is inherent to the growth precursor. ${ }^{13} \mathrm{C}$ isotopic labeling studies' in the growth of $I I-V$ compounds as well as controlled addition of hydrocarbons ${ }^{2,3}$ have confirmed that carbon onginates from the organometallic sources used in the MOCVD process. Carbon behaves as a shallow acceptor in GaAs and AlGaAs, and its incorporation has atracted considerable attention ${ }^{i-3}$ both as an undesirable contaminate, resulting as a by-product of the growth reactions, and as a key to understanding the growth chemistry. As opposed to these extensive studies of carbon incorporation in GaAs, the problem has not been pursued for epitaxial ZnSe grown by MOCVD and the optoelectronic behavior of carbon impurities in ZnSe has not been characterized. Specifically, no peak in the photoluminescence (DL) spectrum of $\mathrm{ZnSe}$ is known to be related to or tentatively attributed to carbon. We report here the first experimental evidence for carbon incorporation in $\mathrm{ZnSe}$ grown by MOCVD, and correlate the presence of carbon impurities with a $P L$ peak, appearing only in carbon-contaminated films.

Methylally lselenide (MASe), a novel organometallic Se source, was used to grow ZnSe films in a loadiock-equipped, vertical stagnation point flow MOCVD reactor. A mass spectrometer system with a sampling port immediately downstream of the susceptor was used to monitor stable reaction by-products. Further details of the reactor design, control, and gas handing system will be pubiished elsewhere. ${ }^{4}$ Electronic grade dimethylzinc (DMZn) was used as the $\mathrm{Zn}$ source. The $\mathrm{ZnSe}$ films were grown epiraxially on semi-insulating (100)GaAs substrates, misoriented $2^{\circ}$ towards $\langle 110\rangle$. The substrates were degreased and etched according to standard procedures ${ }^{5}$ before being placed on a Mo susceptor inside the load lock. The reactor was pumped down to a base pressure of $1 \times 10^{-8}$ Torr and then purged overnight with $\mathrm{H}_{2}$ at low pressure prior to growth. After transferring the substrate into the main reactor chamber, the deposition sequence was initiated with native oxide desorption in $1 \operatorname{sin~} \mathrm{H}_{2}$ flow at $650^{\circ} \mathrm{C}$ and a total reactor pressure of 300 Torr for 10 min. After a short adjustment to the growth temperature $\left(T_{G}\right)$, growth was initiated by simultaneously flowing the MASe and DMZn (diluted in $\mathrm{K}_{2}$ ) into the reactor. The ZnSe films were grown at 300 Torr and $520^{\circ} \mathrm{C}$ with constant DMZn flow rate at $20 \mathrm{\mu mol} / \mathrm{min}$, while the molar flow rate of MASe was varied from 10 to $120 \mu \mathrm{mol} / \mathrm{min}$. The variation in the $\mathrm{V} / \mathrm{LI}$ ratio resulted in different carbon incorporation in the flims.

Measurement of the caroon impurity levels in ZnSe was performed by secondary-ion mass spectronetry (SIMS) with a detection limit for ${ }^{12} \mathrm{C}$ around $1 \times 10^{18} \mathrm{~cm}^{-3}$. A nominally undoped $Z n S e$ film grown by molecular beam epitaxy (MBE) and showing no detectable carbon impurities was implanted with ${ }^{12} \mathrm{C}$ to provide an internal standard for SIMS measurements of the carbon concentration in the MOCVDgrown $Z$ nSe films. The implant had a peak ${ }^{12} \mathrm{C}$ concentration of $1 \times 10^{20} \mathrm{~cm}^{-3}$. The SIMS measurements ${ }^{6}$ were carried out with a Cameca IMS-4f spectrometer using a $\mathrm{CS}^{+}$primary ion beam with an incident energy of $14.5 \mathrm{keV}$ and an ion current of $150 \mathrm{nA}$, rastered over an area of $250 \times 250 \mu \mathrm{m}^{2}$. Negative secondary ions were monitored. Depth scales for the SIMS profles were determined from measurements of the crater depths with a calibrated profilometer.

SIMS depth profiles of the ${ }^{12} \mathrm{C}$ peak are shown in Fig. 1 for ZnSe films grown by MOCVD from different source combinations as well as by MBE. The apparent higher carbon levels in the buik GaAs than in the bulk $\mathbb{Z n S e}$ for curves (a) $-(c)$ are believed to be due to differences in SIMS sensitivity (detection limit of ${ }^{12} \mathrm{C}$ ) in the two lattice matrices. Growth from $M A S e / D M Z n$ at $V I / I=1$ results in a $f l m$, which shows a dramatic increase of several orders of magnitude of the ${ }^{12} \mathrm{C}$ concentration in a region near the $\mathrm{ZnSe} /$ GaAs interface, as illustrated by curve (a) in Fig. 1. This is 


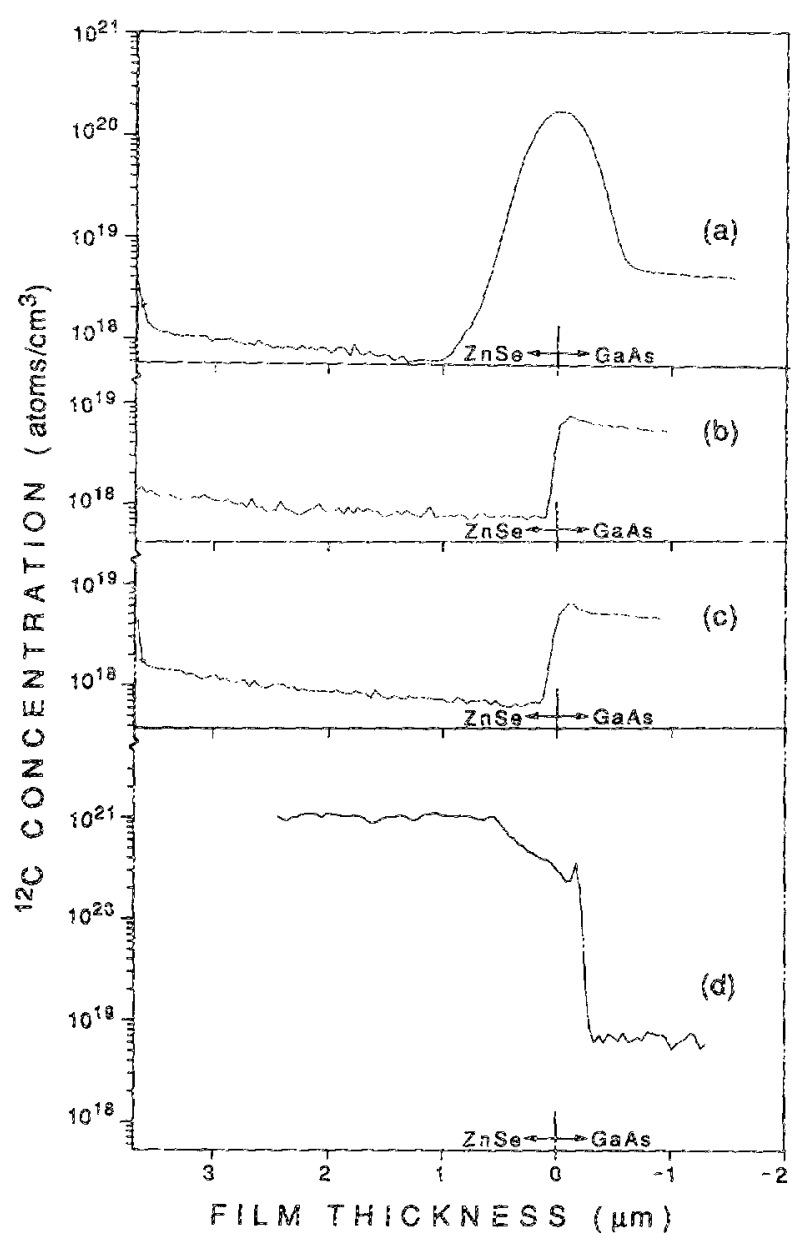

FIG. 1. Carbon depth profiles for diferent $Z$ nSe films detected as ${ }^{2} \mathrm{C}-$ ion by SIMS. The position of the $\mathrm{ZnSe} / \mathrm{GaAs}$ interface is estimated by monitoring the molecular ion ${ }^{13 \%} \mathrm{ZnSe}$ - (a) MOCVD-grown film from MASe/ $D M Z n$ at $V I / I I=1$. (b) MOCVD-grown fim from $H_{2} S c / D M Z n$ at $V L /$ $\mathrm{II}=10$, immediately after film (a) in the same reactor. (c) MBE-grown aim. (d) MOCVD-grown fim from $\mathrm{MASe} / \mathrm{BM}$.n as $\mathrm{VM} / \mathrm{L}=4$.

not due to surface preparation effects; growth of ZnSe from $\mathrm{H}_{2} \mathrm{Se} / \mathrm{DMZn}$ at $\mathrm{VI} / \mathrm{MI}=10$ in the same MOCVD system, immediately after the MASe experiment and with the same preparation sequence, produces material for which the "bump" in the carbon concentration at the ZnSe/ GaAs interface is absent as shown in curve (b), Fig. 1. The depth profile (c) is for a ZnSe sample grown by $\mathrm{MBE}^{8}$ on the GaAs substrate, cleaned in a manner similar to the other ones and preheated in vacuum for oxide desorption. Again the carbon concentration is below the detection imit and no signifeant increase in carbon is observed near the interface. Therefore, it appears that the large ${ }^{12} \mathrm{C}$ signal near the $\mathrm{ZnSe} / \mathrm{GaAs}$ interiace is $d$ ue to the incorporation of ${ }^{12} \mathrm{C}$ impurities originating from the organometallic Se precursor, MASe.

The ${ }^{12} \mathrm{C}$ concentration in the bulk of 2 nSe sample grown from MASe/DMZn at VI/MI = 1[Fig. 1 (a)] is at the detection limit of our SIMS apparatus. When the flow rate of MASe is increased relative to the DMZn, the ${ }^{12} \mathrm{C}$ concentration in the bulk of the films becomes detectable and at a molar ratio $\mathrm{VI} / \mathrm{I}=4$ the carbon level is almost four orders of magnitude above the detection limit, as illustrated by the depth profile (d) in Fig. 1. The strong variation of the ${ }^{12} \mathrm{C}$

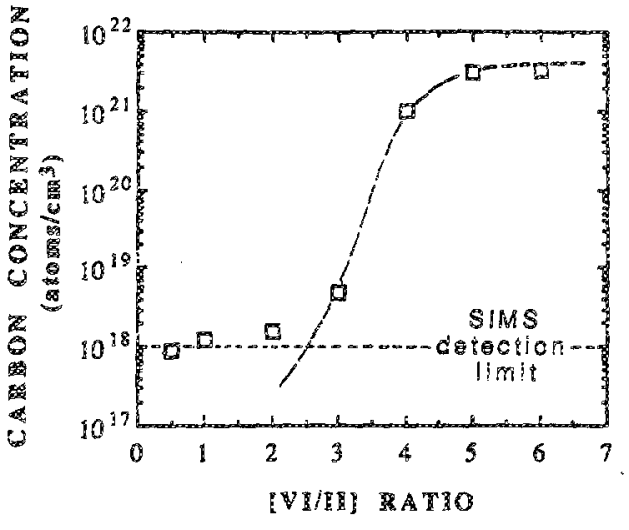

FiG. 2. Carbon concentration in the bulk of ZnSe tims growir from MASe/ DMZn ploted vs the [VI/II] inlet molar ratio.

concentration in the bulk of the ZnSe films (as measured by SWMS) with the VI/II ratio is apparent in Fig. 2. The increase in the amount of incorporated carbon is accompanied by a marked degradation in crystahline quality as evidenced by scaming electron microscopy (SEM) and electron charneling patterns. At the point of the steep change in ${ }^{12} \mathrm{C}$ concentration ( $\mathrm{VH} / \mathrm{II} \approx 3.5$ ), the ZnSe films become polycrystalline. Suck a dramatic change of structures is not observed for similar VI/I values, when $\mathrm{H}_{2} \mathrm{Se}$ or diethylselenide are used as the Se precursors. ${ }^{4}$ The accumulation of carbon at the $\mathrm{ZnSe} / \mathrm{GaAs}$ interface is also likely to be responsible for the peculiar morphology of $\mathrm{ZnSe}$ films grown from MASe/ DMZn reported earlier."

The low-temperature $(9 \mathrm{~K})$ photoluminescence $(\mathrm{PL})$ spectrum of a ZnSe sample grown at $V / L I=1$ is shown in Fig. 3(a). Peak notation and assignment has been reported previously. ${ }^{10}$ In contrast to the $\mathrm{PL}$ spectrum of a typical

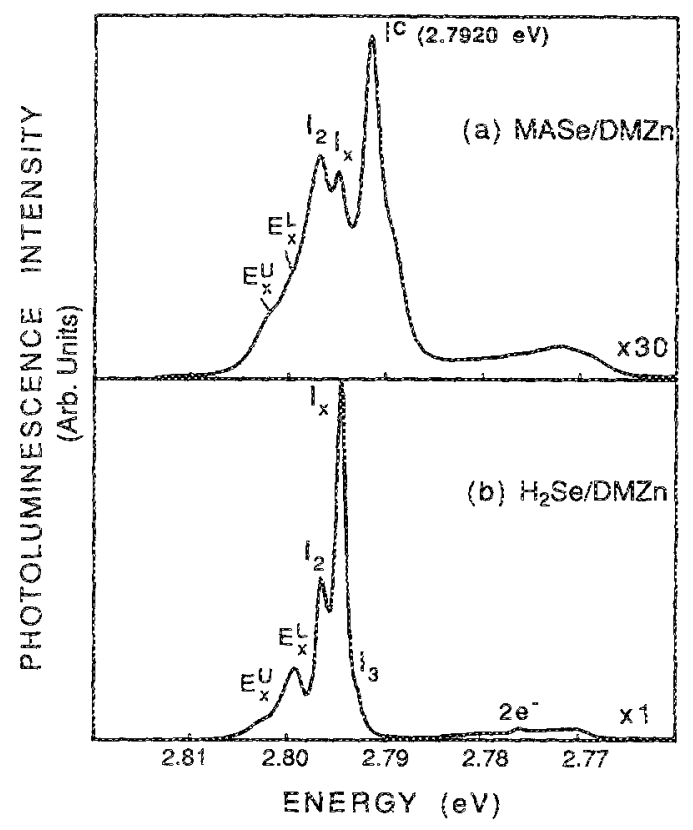

FIG. 3. Expanded near-band-edge $P L$ spectra of $Z$ ns films taken at $9 \mathrm{~K}$. (a) Film grown from MASe/DMZn at VI/IL =1. (b) Film grown from $\mathrm{H}_{2} \mathrm{Se} / \mathrm{DMZn}$ at $\mathrm{VI} / \mathrm{II}=10$, immediately after film $(\mathrm{a})$ in the sane MOCVD reactor. 
$\mathrm{ZnSe}$ sample grown from $\mathrm{H}_{2} \mathrm{Se} / \mathrm{DMZn}$ and shown in Fig. $3(\mathrm{~b})$, the near-band-edge (NBE) emission is dominated by a new shallow $I^{C}$ peak at $22525 \mathrm{~cm}^{-1}(2.7920 \mathrm{eV}){ }^{11}$ In Fig. 4 , the intersity of this peak, normalized to that of the freeexciton peak $E_{x}^{L}$, as well as its linewidth is plotted versus the VI/II ratio. They both increase with the VI/II ratio, showing similar behavior to the carbon concentration as measured by SIMS, while the other peaks in the NBE emission spectra remain unchanged. The $F^{C}$ peak is also observed in $\mathrm{ZnSe}$ grown from diethylselenicie/ $\mathrm{DMZn}^{4}{ }^{4}$ but it is absent in MBE-grown material. Assuming this peak is due to the radiative decay of a bound exciton, the exciton localization energy is 10.7 meV. Haynes' rule ${ }^{12}$ would then give activation energies of 54 and $107 \mathrm{meV}$ for simple substitutional donors or acceptors, respectively, whereas effective mass analysis ${ }^{13}$ yields activation energies of approximately $29 \pm 2$ and $108 \mathrm{meV}$. Selectively excited photoluminescence experiments failed to produce conclusive evidence for two-electron or two-hole transitions, probably due to the broadness of the $I^{C}$ peak. ${ }^{14}$ Despite the coincidence of the predicted acceptor activation energy with the effective mass value, it is unlikely that the binding occurs at a simple substitutional site, but rather at a complex which is associated with the carbon impurity. ${ }^{\text {is }}$ Identification of the nature of this complex awaits further study.

An unidentified $\mathrm{PL}$ peak, often marked as $I_{3}$, has been observed in other MOCVD studies, ${ }^{16}$ especially when dimethylselenide was used as the Se precursor. Although the exact energy of this peak is not reported, estimation from the published NBE spectra in the aforementioned studies yieids positions very close to our $I^{C}$. In addition, the possible connection between this peak and carbon impurities originating from the $\mathrm{CH}_{3}$ - Seo or its pyrolysis products has not been recognized. In a recent study of ZnSe grown by metalorganic molecular beam epitaxy (MOMBE) from $\mathrm{H}_{2} \mathrm{Se} / \mathrm{DMZn}$, Oniyama et al. ${ }^{17}$ found a dominant $I_{1}^{S}$ peak at exactly the same position as our $I^{\circ}(2.7920 \mathrm{eV})$. This peak was observed only when both sources were cracked before deposition, indicating that both methyl radicals and Se atoms were necessary for its appearance in the PL spectra of $Z \mathrm{ZnSe}$ fims.

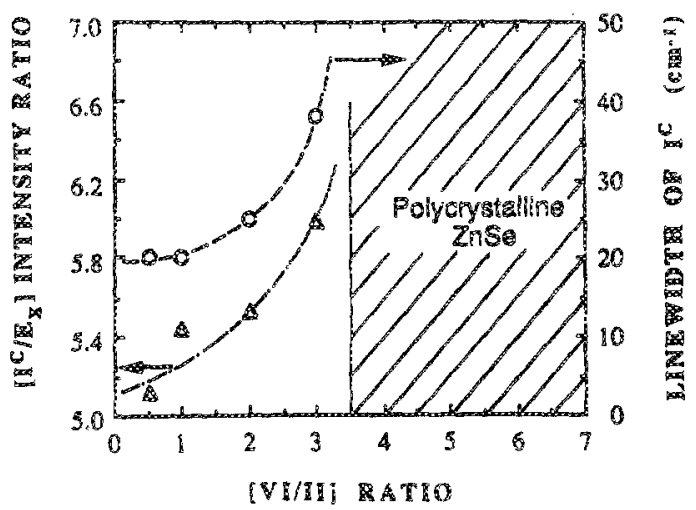

FIG. 4. Normalized PL intensity ratio $\left[I^{\mathrm{C}} / E_{x}\right]$ and the linewisth of $I^{\circ}$ ploted vs the $[V I / I H]$ ratio for ZnSe films grown from $M A S e / D M Z n$. For IV $/ I H \perp \geqslant 3.5$ the films are polycrystalline, resulting in weak, broad, unresolved BL spectra.
The identification of carbon incorporation in ZnSe grown by MOCVD establishes an additional measure for evaluating organometallic Se sources as possible replacements of $\mathrm{H}_{2} \mathrm{Se}$. Since $\mathrm{CH}_{3}$-Se appears to be a significant factor in carbon incorporation, compounds which contain this meiety (such as methylselenol, ${ }^{18}$ dimethylselenide, ${ }^{16}$ methylallylseienide ${ }^{9}$ ) are expected to produce films with sig. nificant levels of carbon. In addition, processing conditions in MOCVD or MOMBE that would lead to $\mathrm{Ch}_{3}$-Se- formation are hikely to be detrimental to film quaity. Confirmation of the $I^{\mathrm{C}} \mathrm{PL}$ yeak as being carbon related by other spectroscopic techniques would yield a usefu! tool for monitoring carbon incorporaton in $\mathrm{ZnSe}$, analogous to the PL procedures used in GaAs studies. ${ }^{2.3}$

The authors are grateful to $G$. Haugen for his technical assistance with the $\mathrm{PL}$ measurements. This work was supported by the National Science Foundation (CBT-8351249) and by a University of Minnesota Graduate School Doctoral Dissertation Fellowship to K. P. G. American Cyanamid is also thanked for providing the methylallyi Se source.

'R. M. Lum, J. K. Klngert, D. W. Kisker, D. M. Tennant, M. D. Morris, D. L. Malm, J. Kovalchick, and $\mathrm{I}$. A. Heimbrook, J. Electron. Mater. 17 , $101(1988)$.

${ }^{2}$ T. F. Kuech, Mater. Sci. Rep, 2, 1 (1987), and references within.

${ }^{3}$ T. E. Kuech, G. J. Scilla, and F. Cardone, 8 . Cryst. Growth 93,550 (1988).

4. P. Giapis, Wh.D. Thesis, University of Minnescta, 1989.

W. Stutius, J. Electron. Mater. 19, 95 (1981).

${ }^{6}$ T. L. Snith, H. Cheng, S. K. Mohapatra, and J. E. Potts, J. Vac. Sci. Technol. B 5, $1326(1987)$.

${ }^{7}$ It is also possible that there is more carbon in the GaAs substrates than the amount incorporated in the $Z$ ns Se films. However, the amount $5-7 \times 10^{18}$ $\mathrm{cm}^{-3}$ (estimated from the profiles of Fig. 1) is not accurate since the SIMS instrument has not been calibrated for GaAs. In fact, it is higher than the manufacturer's specifications (Sumitomo Electric Industries).

${ }^{8}$. M. DePuydt, H. Cheng, J.E. Potts, T. L. Smith, and S. K. Mohapatra, J. Appl. Phys. 62, 4756 (1987).

"K. P. Giapis, D.C. Lu, and K. F. Jensen, MRS Procedings, Vol. 131. Chemical Perspectives of Microelectronic Materials (Materials Research Society, Pittsburgh, PA, 1988), p. 63 .

${ }^{10}$ K. P. Giapis, D.C. Lu, and K. F. Jensen, Appl. Phys. Lett. 54, 353 (1989).

"We have extensively studied doping of ZnSe by MOCVD and MBE using $\mathrm{Li}, \mathrm{Na}$, and $\mathrm{N}$ as impurities. The resulting doped flms had $\mathrm{PL}$ spectra with acceptor-bound exciton positions well removed from the position reported here.

17J. L. Merz, H. Kukinoto, K. Nassau, and J. W. Shever, Phys. Rev. B 6, $545(1972)$.

13R. N. Bhargava, 3. Cryst. Growth 59, 15 (1982).

14. E. Potts, T. L. Smith, and H. Cheng, SPIE Yol. 794. Modern Optical Characterization Techniquex for Semiconductors and Semiconductor Devices (SPIE, Bellingham, WA, 1987), p. 27.

in all of the known cases of group IV incorporation in II-VI compounds, the group IV atom resides on the group II site as is demonstrated by electron paramagnetic resonance experinents [See, for example, $K$. Suto and M. Aoki, J. Phys. Soc. Jpn. 26, 287 \{ 1969 ); 24, 955 (1968) ]. Chemically, this seems reasonable for the case of $\mathrm{ZnSe}$ because carbon forms a strong compound with Se and not with Zn. Therefore, carbon should be (formally) a double donor.

'T. Fujita, A. Tanabe, T. Sakamoto, M. Isemura, and S. Fujita, J. Cryst. Growth 93. 259 (1988); T. Yokogawa, M. Ogura, and T. Kajiwara, Appl. Phys. Lett. 50, 1065 (1987); A. Yoshikawa, S. Muto, S. Yamaga, and $H$. Kasai, J. Cryst. Growth 93,697 (1988).

"H. Oniyama, S. Yamaga, A. Yoshikawa, and H. Kasai, J. Cryst. Growtli 93, 679 (1988).

${ }^{1}$ S. Fujita, T. Sakamoto, M. Isemura, and S. Fujita, 3. Cryst. Growth 87, $581(1988)$ 